\title{
Word Level, Above Level, Grammatical Level, Textual, Pragmatics Level Non- Equivalence: Problem and Strategy
}

\author{
Andi Rustandi \\ Universitas Galuh \\ andru.unigal@yahoo.co.id \\ Syafryadin \\ University of Bengkulu \\ syafryadin@unib.ac.id \\ R.Bunga Febriani \\ Universitas Galuh \\ bunga.febriani@gmail.com
}

\begin{abstract}
This study is aimed at elaborating the non-equivalences in the word level, above level, grammatical level, textual level, pragmatics level in translation process. This study employed the two research questions i.e. what are the types non equivalences emerge in the translation process? and what are the problems and strategy used by the translator that emerge in translation process?. Covering these questions, this study used descriptive qualitative approach by using the library research to gain some references of types of non-equivalences, problems, and strategy used in the object of the study. The result revealed various types of non-equivalences and problems emerge from the translation process and some strategies also used by the translator to cover the problematic issues on the non-equivalence in translation process.
\end{abstract}

Keywords: Word Level, Above Level, Grammatical Level, Textual, Pragmatics Level NonEquivalence

\section{A. Introduction}

The notion of translation has been defined by some experts with different perspectives. For example, Bell (1991: 5) defined translation as the utterance to another language of what has been expressed in other source languages, maintaining semantics and stylistics equivalences. However, by focusing to the meaning as a significant element, Ghazala (1995) clarified that translation refers to all the process and methods used to convey the meaning of the source language into the target language.

This notion implies that when doing translating, understanding the meaning of source text is vital to get the appropriate equivalence in the target text. Thus, it is the meaning that is central in the translating process concerning the used grammar, style and 
sounds. However, Catford (1995) simplified the notion of the replacement of textual material in one language (SL) by equivalent textual material in another language (TL). From the definition above, the concept of translation can be excerpt as the effort to maintain the source text to have an equivalence expression towards the target text. The equivalence can be categorized in a different level such as word, above word, grammatical, textual and pragmatic (Baker, 2011).

The concept of equivalence in translation is postulated to be a central issue in translation, although its definition relevance and applicability within the areas of translation theory. Some researchers have elaborated this concept of equivalences recently such as Baker (1992); Nida and Taber (1982); and Vinay and Darbelnet (2000). However, this conception faced some controversies due to asymmetric, directional, subjective-less and ill-defined in judging the text (Bolanos in Kashgary, 2011). Besides, Kashgary affirmed that the concept of equivalence needs re-adjustment to cope with translation judgment.

Based on the concept above, the notion of non-equivalence also commonly occurs in the translation process from one source language (SL) to the target language (TL). There is an occurrence of non-equivalence when the translator cannot meet the goal of SL to TL due to the language and culture diversity, and different views of the translator in translating process. Concerning the notion above, this argumentative essay attempt to seek the asymmetric (nonequivalences) in terms of world level, above level, grammatical level, textual level, and pragmatic level provided by the problematic issue and its strategy from different authors in different parts of translation.

\section{B. Research Methodology}

This study used a qualitative approach by using library research. According to George (2008), "library research" involves identifying and locating sources that provide factual information or personal/ expert opinion on a research question; a necessary component of every other research method at some point". Accordingly, related information and data were extracted from various documents, mainly official website, government report, thesis, and journals. Therefore, this study uses the groundwork of library research method which form the theoretical framework of this study by searching, reading and evaluating some journal from the online journal that deals with the topic (Booth, 2016). In the present article, therefore, several journal articles retrieved from the online journal's website were taken to 
elaborate the conception of the non-equivalences and problematic issues in translation process.

\section{Result and Discussion}

\section{Non-Equivalences, Problems, and Strategy}

The conception of non-equivalence commonly happens in translation process. It might happen due to language diversity and different language features of the different languages. Regarding this notion, Baker (1992:20) affirmed that non-equivalence commonly happens when the target language has no direct equivalent in the source text. The common problems are due to the level of the word, above word, grammatical, textual and pragmatics (Baker, 2011), lexical and cultural (Taamneh, 2018). Referring to the notion of nonequivalences above, some articles will be reviewed to find out the types, problematics issue, and the strategy used by the translator at the word level, above word level, grammatical level, textual level and pragmatics level and its strategy to overcome the problem.

\section{Word level non-equivalence}

Word level non-equivalence happens when the word in the target language is not similar to the source language. In a similar argument, (Baker, 2011) explained that nonequivalence at the word level means the word of target language has no direct equivalence in the source language. This argument is also affirmed by the scholars from different field of research such as Fitriani,(2010); Ezzati, (2010) and Dzikrullah (2009).

Fitriani, (2010) found the non-equivalences of word-level in translating the novel "Twilight" from English into Indonesia in terms of number (plurals and singular), gender (she/he), and tense (verb). This non-equivalence emerges as a result of the linguistics differences between English and Indonesia. To cope with word-level non-equivalences conception, the translator employed translating it to general word, specific word, more neutral/less expressive, more expressive word, cultural substitution, loan word and loan word plus explanation, paraphrasing the related word, paraphrasing the unrelated word, omission, and addition. In the same notion, Ezzati (2010) elaborated the non-equivalence in the word level types such as gender, tense and singulars and plurals in translating English text into Persian. In addition, he affirmed that these types of non-equivalences emerged as a result of 
cultural-specific concept. In brief, he found only three strategies were used to overcome this issue, among of them are using the more general word (superordinate), omission, different expression by modifying.

Similarly, Dzikrulloh (2009) found that the world level non-equivalence types as proposed by Backer (2011) obviously existed in the translation text of subtitle "Troy" novel from English into Indonesian. He found the world level non-equivalences happened due to several problematic categories such as culture-specific concepts, lexical, semantic, distinctions in meaning, super-ordinate, specific terms (hyponym), physical or interpersonal perspective, expressive meaning, differences and frequency and purpose of specific forms, and the use of loan words in the source text. Referring to the problems in the word level, he argued that several strategies used by the translator, i.e. general word, specific word, more neutral/less expressive, more expressive word, cultural substitution, loan word and loan word plus explanation, paraphrasing the related word, paraphrasing the unrelated word, omission, and addition.

In contrast, in translating English into Finish, for example, Arfman (2010) noted some findings non-equivalence in word-level as proposed by Baker, (2011). The problems arose due to word length, cultural differences word, and specialized word terminology. In addition, to overcome the incoming problem, he reported that replacing the word with appropriate culture word and literal translation. However, in the study of the comparative translation of functional equivalence of English and Spanish in business text, Gozalez (2010) found that some word-level non- equivalent in terms of vocabulary meaning functional text and word terminology. In this case, the translator generally uses borrowing strategy from the original term and doing translating word by word, which is followed by an explicitation to avoid the inaccurate bilingual dictionaries. In addition, the use of a neutral term was used to make the text mode acceptable for the reader of Spanish.

Briefly, non-equivalences of word-level revealed the same types proposed by Baker (2011), although the translation texts were slightly different in the field of translation. In this regard, the types of word-level non-equivalence revealed to Baker's type of nonequivalence concept, when SL's culture specific concept, lexical, semantic, super-ordinate word cannot meet the goal of the TL. Accordingly, some strategies also rely on Baker's types of strategic conception to overcome the problematic issue. i.e. using more general word, 
specific words, more neutral word, word by word, expressive word, cultural substitution and loan words.

\section{Above word-level non-equivalence}

The non-equivalence in term of above word level might be happened because word is not alone, it almost always in the company of others words to construct meaning. Because of the differences lexical patterning or source language and target language, the translator usually finds difficulties in translating. Lexical patterning difficulties deal with collocation and idiom and fixed expressions. The examples of investigation have obviously discussed and found the problematic phenomena of translation on the above word level and its suggested strategy.

Dzikrulloh, (2010) explained that problems of non-equivalence are on the idiom and colocation in translating the text from English into Indonesia. Idiom and collocation are difficult to translate where there is no synonym or near-synonym in the target text. Some suggestion to cover idiomatic and collocation problem, he proposed the idea of Backer types of strategy by giving additional word and also omitting the unnecessary word. Another problematic in idiom and collocation emerge in the investigation of Cha (2007) in translating the text of nursing form English into Korean. The result affirmed that idiomatic occurred when the text of English does not find a similar expression in the Korean. Covering this idiomatic non-equivalence, the translator preferred to use back-translation to get familiar with the real meaning.

Idiomatic and collocation seems to be problematic points when translating from English into Persian due to the different perspectives of the translator in viewing the two languages that have a different culture in terms of context and meaning (Shojae, 2012). He found the idiom were not translated well similarly into TL, although it is similar but it has different meaning. In addition, four suggested strategies to cope with this problem such using an idiom of similar meaning and form, Using an idiom of similar meaning but the dissimilar form, translation by paraphrasing. and translation by omission.

Throughout different parts of the study above, it was shown that there are some difficulties regarding the translation of idioms and fixed expressions (collocation). The idiomatic non-equivalence might happen because of the cultural differences and language differences. if the translator is not familiar with the idiomatic and collocational expression, it 
can lead to misleading and misinterpretation (Baker,1992). Therefore, the translator might have the strategy to cope with this notion such as addition, omission and paraphrase the text.

\section{Grammatical Level Non-Equivalences}

Grammar is obviously as a set of rules that determine the way in which units such as words and phrases can be combined in a language and the kind of information which has to be made regularly explicit in utterances. The language expresses any kind of information its need to express, but grammar of a given language will determine the ease with which certain notions such as time references or gender can be made explicit” (Baker, 2011, p. 92). In addition, the term grammar is often used to refer to morphology and syntax together. Following are the example of the study on non-equivalence in grammatical level and its strategy found by researchers in a different part of the field.

Dzikrullah, (2010) described the types of non-equivalences in grammatical level in terms number, gender, person, tense and aspect, and voice in a comparative study of the novel "Troy" between English and Indonesia. The problems of non-equivalence emerge when the two languages have different linguistics patterns such as plural and singular in number, the third person singular in person and gender, and the concept of past perfect tense and present perfect. Covering this notion, some strategies were suggested, such as omitting the relevant information and encoding the information lexically. However, Cha et al, (2007) found different types of non-grammatical equivalences in word order, punctuation, verb nuance and tense in comparing the text of English and Korean. In addition, Cha et al. found the omission of unnecessary word and addition the words to keep the sentences or the phrase equivalent.

Another study also found the same types of grammatical non-equivalences. For example, Fargal \& Sunaq (2010) in their study of comparing Arabic-English translation text, found that copulative sentences, past tense, word order, passivization, modality were the problem in the translation process. Meanwhile, the strategy to cope with this notion, borrowing, literal translation, descriptive translation, cultural approximation, paraphrase and omission as the option are meaningful.

Overlooking the grammatical non-equivalences above, most of the study faced the same problem types, which is suggested by Baker (1992) in terms of gender, tense, person, 
word order, passive. Although Fargal \& Sunaq added other types such as copulative sentence and modality, the same strategy used to cope with these problems, i.e. omission, addition, borrowing. In brief, grammatical non-equivalences will always be existed in the translation process due to cross-cultural diversity and linguistics diversity. Still, the strategy might be similar from one language to the other language.

\section{Textual Level Non-Equivalence}

The texture is an essential feature in translation since it provides useful guidelines for the comprehension and analysis of the ST which can help the translator in his or her attempt to produce a cohesive and coherent text for the TC audience in a specific context. Leonardi, (2000) elaborated the textual equivalence when referring to the equivalence between an SL text and a TL text in terms of information and cohesion. She argued that "it is up to the translator to decide whether or not to maintain the cohesive ties as well as the coherence of the SL text, the decision will be guided by three main factors, that is, the target audience, the purpose of the translation and the text type". The notion above indirectly implies that non-equivalence will happen when SL text does not coherently and cohesively relevant with the TL.

According to Triastika (2017) textual non-equivalence emerged in her study in investigating the translation of the text book from English into Indonesian. She found that cohesive device changed and shifted in term of different number of references. In addition, aberration, which is not directly related to the pattern or arrangement of thematic structure, information structure and cohesive devices translation contained in the TT. She added that socio-culture differences become the main reason of the translator background. Completely, four deviations such as aberrations of referential meaning and deviation of grammatical meanings are obvious. In covering to this idea, she found literal translation strategy is used by the translator. However, Azmina (2018) found non-textual equivalences in translation English into Indonesia language of Christopher Paolini's Novel of "Inheritance". She found textual cohesion on different personal references, different substitution and ellipsis, different lexical cohesion and the strategy to cover the problem of are substitute the reference and reiteration.

In conclusion, based on the study above, the types of textual level and the strategy explained in different types of text. Cohesive devices, referential number and person, lexical 
cohesion as the major types emerged in the text used by the translator. Thus, literal translation, substitution and ellipsis and substitution are commonly used by the translators.

\section{Pragmatics Level Non-Equivalence}

Newmark (1988) defined translation as rendering the meaning of a text into another language in the way that the author intended the text. The definition suggests the importance of maintaining the original author's intended meaning in the translated text. It implied that pragmatics as the study of meaning in context is important in translation to get the reader clear from any ambiguous meaning. However, due to different culture and different view of the translator background the non-equivalence might be happened. Prozinskaya (2015) tended to use the term non-coinside for the notion of the non-equivalence in pragmatic level. However, Zaki (2000), affirmed that meaning of a given word or set of words is best understood as the contribution that word or phrase can make to the meaning or function of the whole sentence or linguistic utterance where that word or phrase occurs.

Prozinskaya (2015) found the pragmatics non-equivalence in her study of illocutionary act in translation text of English and Russian version on "Sholokhov's and quiet flows the Don". She found the types non equivalences emerge directive is represented by requestive verb, assertive verb, infinitive verb. In this regard, the translator reveals and realizes the utterance's communicative direction strategy by using the illocutionary verbs ask and declare which conform to the illocutionary force of the original Russian text.

In contrast, Yuliasri (2016) found pragmatic non-equivalences on humorous utterances in the translation text of English and Indonesian version of Donald Duck Comic. The findings revealed that the translated text has not pragmatic force equivalence due to the implication, discursive creation, reduction, adaptation, and modulation of the words. It can be inferred that some techniques such as using more general word, literal translation, borrowing, calque, and transposition. In addition, In the study of English and Arabic version, Triki, (2013) found the pragmatic non-equivalence types denotative and connotative expression, religious dimension utterance, ambiguous utterance, and a culturally loaded expression in students translation text. As a result, he pointed out the strategy such avoidance strategy, word for word translation, and literal translation.

In brief, pragmatic non-equivalence arises throughout the research above. The types of the pragmatic level are on the implicature and speech act such as in connotative and 
denotative expression. The problems behind the issue are due to the cultural background knowledge of the translator. Finally, concerning this issue, the translator used word by word translation, literal translation, and more direct communicative strategy to cover this issue.

\section{Conclusion}

Throughout different parts of the articles, it is shown that there are similarities of the translation problems. It can be categorized as the types proposed by Baker, (1992) i.e. voice, gender, tense and aspect, a person at word level and grammatical level. However, in the textual level, the non-equivalence types emerge such as cohesive device changed and shifted in term of the different number of references. Additionally, in pragmatic level the types of non-equivalences refer to implicature in speech act such as the requestive verb, and assertive verb

The problematic issue emerged as the result of the culture specific-concepts, and the difference in expressive meaning at the word level, above level, textual level and pragmatic level. The problematic factors are due to the diversity of language and culture and the translator background.

Finally, some techniques to overcome these difficulties such as borrowing, loan, substitution, ellipsis, addition, omission, neutral/ less expressive and transposition have been mentioned. Another key concept to be considered is translators who are supposed to have a perfect knowledge in both source language and target language. As a result, it is essential for a translator to know both languages as well to cover with the problems of non-equivalences to preserve the equivalence in both of the text.

\section{References}

Arffman, I. (2010). Equivalence of Translations in International Reading Literacy Studies. Scandinavian Journal of Educational Research. 54(1), 37-59. Routldge. Taylor and Francis Group.

Bell, R.T. (1991). Translation and Translating: Theory and Practice. London:Longman Azmina, B. (2018). The analysis of grammatical and textual equivalences used in the translation of Paolini's novel of "Inheritance” into Indoensian. IAIN Salatiga.

Baker, M. (1992). In Other Words. A Coursebook on Translation. London: Routledge 
Baker, M. (2011). In Other Words: a course book on Translation. London and New York: Routledge.

Cha E.-S., Kim K.H. \& Erlen J.A. (2007). Translation of scales in cross-cultural research. Issues and Techniques Journal of Advanced Nursing. 58(4), 386-395.

Catford, J. (1995) A linguistic Theory of Translation. London. Oxford University Press.

Dzikrullah, B. 2010. Word, Above Word, and Grammatical Equivalence in the Subtitle of Troy. Thesis of State University Of Semarang, English Department Language and Art Faculty.

Ezzati, A. (2017). Non-equivalence at idiomatic and Expresional level and the strategies to deal with: English translation into Persian. International Journal of Comparative Literatuture \& Translation Studies. 5(4), 2.

Farghal, M., \& Shunnaq (1998). Gramatical void: A theoretical perpectives. Translation Journal, Vol 6, 1, 79-89.

Ghazala, Hasan, (1995) Translation as problems and solutions (4th ed.) Syria: Dar Elkalem ElArabi.

Kashgary (2011). The paradox of translating the untranslatable: Equivalence vs. nonequivalence in translating from Arabic into English. Language and Translation Journal. 23(1), 47-57

Leonardi, Vanessa. 2000. Equivalence in Translation between Myth and Reality. Translation Journal. Vol.4, No. 4. http://www.accurapid.com/journal.

Nida, E. and Taber, C.R. (1982). The Theory and Practice of Translation. Leiden: E.J. Brill.

Newmark, P (1988). A text book of translation. New York. Prentice Hall

Taamneh. (2018). Translating Selected Arabic Literary Items and their Point of Views behind these Problems. International Journal of Applied Linguistics \& English Literature, 7(5), 77

Triastika, H. (2017). Textual Equivalences in the translation of English text into Indonesian. International Journal of Language Education and Culture Review . 3(1), 3.

Triki, M. (2013). A pragmatics approach to the study of English/ Arabic Translation Errors. Journal Academica, 3(1), 39-51. www.journalacademica.org

Vinay J. P. and J. Darbelnet. (2000). “A Methodology of Translation.” In L. Venuti The Translation Studies Reader (pp. 84-91). London and New York: Routledge. 
Yuliasri, I. (2016). The translation techniques and pragmatics equivalence in Indonesian translation of humorous utternces in the Walt Disney's Donald Duck. Prosiding Parasati: PPS UNS

Zaky, M.M. (2000). Translation and meaning. Translation Journal. 4(4),1. 